Ciências 



\title{
Do estilo em ciência e em história das ciências
}

\author{
MICHEL PATY
}

\section{Racionalidade e historicidade do conhecimento científico considerado como pensamento simbólico}

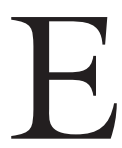

NQUANTO atos e frutos do pensamento, os conhecimentos científicos se apresentam como formas simbólicas, sem que essa qualificação nada lhes retire de sua dimensão prática e material e de seus efeitos concretos. De uma maneira geral, o pensamento simbólico pode ser visto como a marca propriamente humana da presença no mundo. A linguagem e os mitos, outras formas do pensamento simbólico junto com o conhecimento científico tais como as considerava Ernst Cassirer (1923-1925), produzem igualmente efeitos no mundo social (e psicológico) e no mundo material. As ciências, em particular, que estabelecem, transformam e aplicam saberes “objetivos", pertencem, pela natureza de seus enunciados, à ordem do simbólico (a da linguagem, dos conceitos, das teorias, das representações do mundo); mas elas não se limitam a esses enunciados, compreendendo também os atos práticos sobre os objetos e os fenômenos, materiais e sociais, estabelecidos ou transformados por esses enunciados mesmos. O simbólico, no qual se exprime o pensamento humano, não se reduz a signos abstratos, totalmente depurados, ele possui uma densidade material que é a dos conteúdos significados, mas também a dos seres carnais, vivos e pensantes que estabelecem esses conteúdos ou os recebem, a de seus atos, seus "gestos" e suas relações intersubjetivas e sociais. Pois é somente assim que esses conteúdos adquirem sentido e são efetivos.

Consideremos, por exemplo, os conceitos científicos, que são os elementos da descrição em forma de representação ( simbólica), formados por uma ciência no domínio que ela tomou por objeto (e que se aplicam a fenômenos naturais, ou sociais, ou mentais, ou ainda a propriedades ou construções formais como as da matemática e da lógica). A elaboração desses conceitos corresponde a uma atividade do pensamento guiada pelo projeto de explicar o dado fatual relativo a esse domínio, transposto segundo as modalidades do pensamento, isto é, em elementos simbólicos e em relações entre esses elementos. Os conceitos se apresentam assim como símbolos racionais abstratos (sem identidade de natureza com o que eles designam). Mas esses símbolos são bem mais do que simples signos, pois possuem conteúdos de sentido complexos que fazem deles, para o pensamento, os substitutos da "realidade exterior concreta" que designam e que os tornam, por assim dizer, igualmente concretos, pelo menos 
num certo sentido. De fato, eles adquiriram carne e sentido pela experiência e na história.

A especificação cada vez mais consciente do projeto de conhecer o "mundo" (designando com isso "o que é", não importa o que seja, exterior aos pensamentos singulares, mas que se manifesta a eles, que o experimentam) é característica do movimento do pensamento científico que conhecemos. Ela se realiza pela diferenciação e a generalização da posse efetiva desse pensamento sobre o mundo, mundo da natureza e das formas, mas também das relações humanas e sociais, que constatamos com a diversidade das ciências e das epistemes correspondentes, específicas de seus objetos e domínios. Aqui é importante levar em conta a diversidade das ciências, considerando todo o leque que vai das ciências da natureza às ciências humanas e sociais, sem esquecer as ciências que tratam de objetos formais. Cada ciência, nela mesma, é limitada em seu domínio e não pode pretender dar conta da totalidade das experiências humanas e do conhecimento do mundo.

Junto com o caráter simbólico de todo conhecimento, um outro traço essencial a considerar é que o centro de toda inteligibilidade e de toda formação (ou mesmo de toda criação) de conhecimento simbólico é o sujeito individual. Esse compreende a dimensão intelectual (relacionada ao pensamento por conceitos e à função do entendimento), mas inclui também outras dimensões (afetiva, estética, ética etc., sem omitir as bases físicas dessas disposições, a saber, os próprios corpos). Claro que se deve privilegiar, nessa consideração, o caráter objetivo do conhecimento uma vez estabelecido, e valorizar o que contribui a estabelecê-lo como tal, caracterizando suas bases epistemológicas, a saber, a função do racional, os conceitos e a teoria, bem como a atenção à experiência e os critérios de validação que compreendem a crítica (racional também). Mas as outras funções do pensamento, que se apagam nas formulações em termos de conteúdos cognitivos objetivos, desempenham seguramente um papel na interiorização intelectual que produz a compreensão num sujeito individual.

No leque dos conhecimentos de que falamos, a história ocupa um lugar particular para o nosso propósito, pois seu objeto não é senão o conjunto das atividades humanas inseparavelmente ligadas às suas diversas representações simbólicas, apreendidas segundo os tempos e os lugares: Marc Bloch (1949) a definia como a "ciência dos homens no tempo". Ora, a história recorre de saída, para caracterizar seus objetos assim como seus métodos, às produções simbólicas cuja memória ela se propõe constituir. Se para isso deve recorrer a interpretações e à hermenêuti$\mathrm{ca}$, ela busca, no entanto, a maior objetividade possível quanto às suas fontes e a seus arquivos, que são os traços concretos ou escritos das produções e dos efeitos dessas representações simbólicas em sua diversidade (e também em suas relações).

\section{A dimensão temporal do conhecimento científico} e a tensão dinâmica entre o sujeito do conhecimento e a objetividade

Uma das características essenciais dos conhecimentos científicos (para nos atermos a eles, mas isso vale igualmente para as outras formas de conhecimento 
nas sociedades humanas) é a de serem produzidos e transformados ao longo do tempo. O que chamamos "a ciência" é fundamentalmente não estático. Comporta uma dimensão temporal intrínseca que se manifesta na sua dinâmica, visível tanto nas mudanças de conteúdos de conhecimento quanto no movimento mesmo da atividade científica e nas transformações ligadas a seus efeitos. E, antes dessas mudanças, na formulação dos conhecimentos, que não estavam dados como tais na natureza e que, portanto, foram inventados ou criados no seu próprio espaço simbólico.

Esse aspecto dinâmico tornou-se muito aparente com a ciência moderna e contemporânea, desde o século XVII: o aumento e a integração de todos os conhecimentos adquiridos incitam a formar a ideia de um "progresso". Notemos simplesmente aqui que essa noção, que parece bem justificada para os conteúdos cognitivos das ciências consideradas na história, transforma-se em ideologia tão logo se pretende estendê-la sistematicamente fora do domínio que é o da sua verificação fatual (que mesmo assim implica julgamentos normativos): ela carrega então todas as ambiguidades das relações entre ciência e sociedade.

A dimensão temporal e o caráter dinâmico indicam imediatamente um vínculo com a história. É verdade que as ciências existiam antes de serem pensadas na história e antes que a história fosse pensada como ciência; mas não é menos verdade que, vistos hoje em nossa perspectiva, os conhecimentos científicos se constituíram e se transformaram na história. A consideração desse estado de coisas constitui o objeto da história das ciências.

A história humana é evidentemente o cadinho do que se forma e se transforma, do que é posto à prova por meio da experiência vivida. Ela é o campo em que se revela uma tensão entre o papel insubstituível do sujeito (psicológica, social, intelectual, historicamente situado) e o caráter objetivo do que ele contribui a manifestar.

Assim considerada, a tensão entre o sujeito individual, inventor ou receptor de conhecimento, e a objetividade requerida deste último não implica uma contradição insolúvel que obrigaria a escolher somente um de seus termos (segundo um esquema lógico abstrato e atemporal), destruindo assim qualquer possibilidade de conceber uma dinâmica genérica, imanente, do conbecimento científico e da racionalidade que o estrutura. Ao contrário, essa tensão aparece como a fonte mesma dessa dinâmica, se admitirmos que a busca de conhecimento, como pensamento, é motivada e orientada pela exigência de inteligibilidade.

Importa, pois, fazer sobressair aquilo que nas duas noções consideradas, a de sujeito individual e a de objetividade, permanece essencial em relação aos estados de coisas constatados que dizem respeito ao conbecimento científico e sua dinâmica "interna" (entendemos com isso: expresso em termos de formas simbólicas significantes). Reencontraremos a mesma exigência quando examinarmos a dimensão da história, que é o campo no qual se desdobra a dinâmica do movimento dos conhecimentos. Tentaremos assim depurar desde o início essas 
noções (de sujeito e de objetividade) de todas as conotações acrescidas cuja função é ideológica e não mais cognitiva, e que são um obstáculo à consideração das duas conjuntamente quando apresentadas como mutuamente exclusivas.

A inteligibilidade reforça e especifica o papel do sujeito individual de maneira ainda mais profunda do que o faz o conhecimento: podemos defini-la como a apropriação pela razão, nos pensamentos subjetivos singulares, de determinado elemento de conhecimento.

É lícito, portanto, erigirmos o sujeito individual, "epistêmico" no que se refere ao conhecimento, em "sujeito transcendental", mas num sentido um pouco diferente daquele em que o entendia Kant, pela consideração da sua fun$c ̧ \tilde{a} o$ que é formar e julgar conhecimentos para além das contingências imediatas, de acordo com a faculdade de razão. A "transcendência", no sentido em que a utilizamos aqui, não é concebida como fora do mundo, mas como recuo em relação à imersão no mundo, esse recuo e esse distanciamento sendo próprios do homem no mundo material onde se encontra e que o produziu (a isso se liga, aliás, a ideia que ele faz da sua consciência e da sua liberdade).

Em realidade, a noção de sujeito individual ela própria supõe, mais do que engendra, a de intersubjetividade, no campo da qual todo sujeito se constitui na sua singularidade interagindo e se comunicando com os outros. Ela implica assim a dimensão do social. Esta última é a matriz da sua inscrição na história. Trata-se, portanto, de precisar a posição do sujeito como lugar elementar e constitutivo de interiorização dos conhecimentos nessa rede relacional.

\section{$O$ indivíduo e o social na história}

A perspectiva da importância do sujeito individual é relativamente recente na história do pensamento, quando não das sociedades. O desencadear da revolução científica no século XVII abriu as comportas de uma espécie de revolução permanente em que as noções de sujeito individual, de liberdade de pensar e de julgar (livre-arbítrio), e de fazer isso segundo a razão que existe em cada indivíduo, tiveram desde então um papel de incitação considerável. Essas ideias, afirmadas na aurora da modernidade científica (por Montaigne, Galileu, Descartes, Pascal, Espinosa e outros), foram desenvolvidas e amplificadas nos séculos seguintes (de Rousseau a Kant, na Declaração universal dos direitos do homem, a de 1789 e a de 1948...).

Essa consciência se impôs, em nome de valores escolhidos (para a humanidade, pelos povos...), mais ou menos ao mesmo tempo que se aguçava a consciência de pertença social e se aprofundava a perspectiva da história e de seus movimentos. A própria ciência, conhecimento do mundo natural e social, e das noções necessárias a esse conhecimento, chegava por reflexividade, junto com seu poder atual sobre o mundo, à plena dimensão da sua historicidade. E pouco depois as ciências sociais, como a etnologia ou a antropologia e também a sociologia e a própria história, mostravam o quanto o indivíduo é impregnado pela cultura que recebe da sociedade onde nasceu e onde vive: ele partilha seus mitos e seus sistemas de crenças, e seu saber é relativo. 
Desde então nos encontramos diante do seguinte paradoxo: ao mesmo tempo que se afirmava a importância do indivíduo e a exigência de seus direitos inalienáveis numa perspectiva axiológica, houve uma tendência, numa perspectiva cognitiva, a uma abordagem racional e científica dos fatos da história que parecia levar ao apagamento da noção de sujeito (e de acontecimento) como cognitiva ou historicamente significantes. Falou-se de "conhecimento sem sujeito", de "filosofia sem sujeito", de "história sem sujeito", como se a qualificação de objetividade devesse necessariamente eliminar a dimensão do sujeito individual. Essas posições, aliás, podiam se basear em bons argumentos, que recusavam as facilidades da invocação da subjetividade onde essa não tinha função alguma. $\mathrm{O}$ inconveniente da unilateralidade de tais perspectivas foi o mesmo que se pôde facilmente diagnosticar em relação ao estruturalismo, apesar do seu inegável interesse. Em realidade, esse ponto de vista diz respeito à objetividade uma vez essa constituída, e não às condições e circunstâncias da sua constituição.

Paralelamente, assistiu-se (e assiste-se ainda hoje) a afirmações antagônicas e absolutas relacionadas ao "internalismo" ou ao "externalismo" em matéria de história das ciências, como se a atenção às significações próprias dos conteúdos específicos das ciências e, inversamente, àquelas mais recentes da inscrição social das ciências e de sua "história social", devessem se excluir mutuamente. No entanto, deveria ser claro que, embora tudo o que é do homem, seu pensamento incluído, traga a marca do social, nem por isso podemos reduzir os conteúdos significativos das ciências às condições sociais de sua produção: esse reducionismo acaba por suprimir a noção mesma de ciência, incluindo a de ciência social, condenada à autofagia.

Levar em conta a efetividade da ciência entre os conhecimentos e suas condições mais evidentes de possibilidade (a saber, sujeitos individuais que são seus produtores e receptores, inseridos no seu meio, as mudanças desses conhecimentos e o pensamento simbólico que os caracteriza) é algo que obriga a considerar tanto os níveis próprios de significação desses conhecimentos entre a diversidade das formas simbólicas quanto a função dos sujeitos individuais na elaboração e no jogo dessas formas.

Notemos apenas, em relação aos primeiros, que, se uma significação se deixa ver num sistema de conhecimentos, é à interiorização em sujeitos que devemos relacioná-la: sem processos elementares singulares não se pode sequer pensar inteligibilidade alguma, nem criatividade. E, em relação aos segundos, em se tratando tanto de compreensão quanto de criação de ideias, haveremos de convir que, mesmo em circunstâncias sociais determinantes, foi preciso a cada vez que um problema de ordem cognitiva novo se colocasse diante de situações inéditas, foi preciso que alguém (um indivíduo) tivesse uma ideia nova, na qual a maioria dos outros no "meio social" não havia pensado. O ato de criação, técnica, artística ou científica (que faz também parte dos fatos históricos), não pode encontrar explicação nas noções de comportamento-tipo ou médio, de estatística ou de consenso social. E, mesmo sem chegar à "criação" no sentido pleno do 
termo, a observação também se aplica a essa "criação" pequena e relativamente banal que é a compreensão que cada um faz de um certo estado de conhecimento, sobre a qual Poincaré assinalou que não se diferencia fundamentalmente da grande: para a subjetividade, as duas são da mesma natureza.

A história é, pela trama temporal do social, uma das dimensões da ciência, como campo de realização da dinâmica própria desta última em suas transformações; por sua vez, ela se tornou também uma ciência. A história é feita das atividades humanas inseparavelmente ligadas às diversas representações simbólicas correspondentes. Essas atividades, características da espécie humana, bem como suas produções distribuídas no espaço e no tempo, correspondem a uma organização do mundo, geralmente de acordo com um projeto, e são criadoras de significações passíveis de se revelar, em nível coletivo, na trama da história. O artista, o cientista ou o pensador de qualquer época, o sujeito humano individual que pensa e "transcende" o estado do mundo ao colocar-se à distância dele e ao formar julgamentos conscientes sobre ele (no caso do cientista, guiado por seu propósito de objetividade), está ele próprio situado na história que incide também sobre as outras dimensões da vida social e do pensamento, e ilumina em particular o campo cultural que cerca o sujeito.

Mas a relação do sujeito com a história não se constitui num único sentido, o do homem imerso na história. É verdade que, nos seus movimentos de conjunto, a história parece colocar de lado os sujeitos, como a ciência o faz ao proclamar sua objetividade. No entanto, se examinarmos bem, as significações que nela detectamos (e que nós mesmos julgamos enquanto seres humanos singulares) nos remetem, na medida em que são históricas - e não, por exemplo, cósmicas, no sentido puramente físico ou biológico -, às significações sincrônicas que dizem respeito às situações e às épocas estudadas, e que só existiram por intermédio de indivíduos singulares. A ciência histórica implica, por sua possibilidade, uma justa reciprocidade (de princípio) entre o sujeito que a concebe e os seres dos quais ele fala, para que possa reconstituí-los imaginando-os (Bloch, 1949). Esses estão na origem - e são as sedes - das significações e das atividades que o historiador se propõe reconstituir.

A evidência é ainda maior no que se refere às significações e às atividades relacionadas ao conhecimento. De uma maneira geral, as ciências, as artes e as outras instâncias culturais que caracterizam as civilizações não seriam pensáveis sem os sujeitos que são suas sedes elementares. A interiorização (nos pensamentos individuais) é a origem efetiva e a base elementar desses movimentos e dessas realizações. As "grandes tendências" de que fala a história têm por lugar de possibilidade e de realização elementar, do mesmo modo que o processo de objetivação da ciência, os sujeitos individuais e sua possibilidade de agir e se comunicar, entre si, mas também, para cada um, com o mundo. A subjetividade e a singularidade dos pensamentos e das ações humanas, às voltas com o mundo que as cerca, exigem a comunicação de uns com os outros, pela qual esses 
pensamentos e essas ações se inscrevem na história e fazem a História, de uma maneira ou de outra.

A considerar do ponto de vista histórico mesmo as condições elementares da produção da ciência na busca de objetividade, não se pode senão constatar que ela está ligada aos sujeitos individuais, capazes de representação simbólica, sem os quais não haveria conhecimento, nem compreensão e assimilação desse. $\mathrm{O}$ individual e o social dependem um do outro e se constituem mutuamente. Assim não se poderia subestimar o papel do social, em ciência como em qualquer outro campo, mas o simples fato de as representações simbólicas terem uma dimensão e uma importância social é incapaz de explicar, por si só, essas formas simbólicas e decidir sobre seus conteúdos de significação. É insuficiente, para explicar os movimentos das ciências e das artes, invocar consensos sociais produzidos pela época. Em particular, a noção "passe-partout" de "paradigma", muito em voga nos tempos atuais, não pode explicar o aspecto de criação do trabalho científico em todos os períodos, a partir do momento em que algo de novo é pensado. Em troca, as noções de escolas, de tradições, de estilos, ou ainda a de campo científico (esta última proposta por Pierre Bourdieu) são úteis e fecundas para mostrar a inscrição social e histórica das atividades intelectuais e criadoras nas ciências ou nas artes. Elas concedem plenamente um lugar à possibilidade de uma dinâmica imanente do pensamento científico, levando em conta ao mesmo tempo as condições intelectuais e culturais dessas produções, elas mesmas ligadas às transformações sociais.

Sobre esse ponto, concluamos que a história, que tem por objeto efeitos ligados a formas simbólicas, não pode permanecer muda sobre o papel do sujeito na sociedade e que, em particular, o papel próprio do sujeito em relação ao conhecimento (a função de inteligibilidade e de formulação de julgamentos) é irredutível a uma comunidade consensual de indivíduos reduzida à simples dimensão social. Essa conclusão parece ter a força de um teorema. Ela implica uma consistência própria da história que, por assim dizer, torna objetivas, no seu devir, as formas simbólicas produzidas. É talvez aí que a história mais se aproximaria do que chamamos ciência em geral, sua objetividade sendo, afinal, a dessas formas apreendidas na sua temporalidade, e não a da concepção empobrecedora contra a qual Paul Veyne $(1971,1978)$ se insurgia porque não dava lugar ao sujeito e, em particular, ao sujeito criador. Ele via nisso um "reducionismo científico e materialista", mas em verdade não era senão um reducionismo estreitamente cientificista.

\section{Conceber e compreender: o estilo na tecelagem do simbólico}

Nessa etapa da nossa investigação, a noção de "estilo"l revela-se esclarecedora, como modalidade e prática da exigência de inteligibilidade. Nós a convocamos aqui em dois níveis: no nível do historiador que aborda as atividades e as obras científicas do passado nessa perspectiva, e no nível dos cientistas que foram os autores dessas obras que o historiador (das ciências) examina. A questão da 
objetividade está no centro dessa dupla preocupação, pois em ambos os casos ela incide sobre a tensão entre o sujeito individual e o conhecimento produzido, objetivado, o da história e seus movimentos, no primeiro caso, o do conteúdo de um saber sobre o mundo, no segundo caso. A primeira perspectiva é mais "reflexiva", a segunda é "objetal" (ou objetivante). Considerar as duas ao mesmo tempo é certamente uma necessidade para conceber plenamente a historicidade dos conhecimentos científicos e precisar o que é essa historicidade, estando admitido que os conteúdos desses conhecimentos têm vocação a ser objetivos e, portanto, no fim de contas, trans-históricos. Pelo menos esses conteúdos não se deixam dissolver nas condições externas, contingentes, que no entanto asseguraram a possibilidade de sua formulação, e exigem ser levados em conta no seu nível próprio de significação.

O recurso à história, ao movimento da constituição dos conhecimentos imbricados em circunstâncias diversas, oferece um quadro mais exato, mais objetivo (no sentido próprio do termo) do que são os conhecimentos científicos, porque atento aos processos efetivos pelos quais a ciência se constitui e se transforma. Ele permite situar a significação desses conhecimentos (entendidos como pensamento do mundo e como ação sobre ele) captados em suas diversas etapas. Sua intenção vai além da simples descrição de fatos de conhecimento nessa ou naquela época, e tal visão da historicidade corresponde a uma perspectiva racional ligada à exigência de compreender.

As duas abordagens, objetal e reflexiva, que acabamos de mencionar, combinam-se porque ambas tratam de conceber e compreender o que faz sentido na sua dimensão histórica. Objetos de pensamento dotados de significação são produzidos e seu sentido não é apenas relativo. De fato, esses objetos têm uma densidade que sua constituição ou sua construção lhes outorga, pois são produzidos conhecimentos novos que se apoiam sobre conhecimentos que os precederam (nem que seja para derrubá-los) e os tornaram possíveis, fornecendo elementos para pensá-los, recorrendo a critérios de objetividade. Eles são interiorizados em pensamentos que têm por sede cérebros de seres materiais, físicos e afetivos, que os assimilam conforme sua capacidade, de tal modo que adquirem como que a consistência concreta de conteúdos-pensamentos que desempenham no pensamento o papel de substitutos do mundo efetivo, externo a ele. Não é assim, afinal, que podemos dizer que compreendemos o mundo?

Poderíamos resumir o movimento de densificação dos conteúdos de conhecimento que acompanham a história humana recorrendo à ideia de uma tecelagem, que constitui e preenche a forma em superfície e espessura, na trama do pensamento simbólico, a partir de um material tão tênue como um fio quase abstrato, o de um elemento do pensamento imaginativo e racional.

\section{Criação de conhecimentos novos}

Consideremos o processo do pensamento científico tal como se efetua num sujeito individual, seja ele estudante, "homem culto" ou cientista. Esse 
processo é guiado por uma exigência de inteligibilidade que se pode formular globalmente como comum a todos, mas que no detalhe se diferencia em cada um. É o que sabemos bem em relação aos estudantes, que têm percursos e velocidades de compreensão diferentes, mesmo para um conhecimento comumente aceito, e nos quais os bloqueios encontrados não são os mesmos para todos. Mas a história nos revela isso também em relação aos próprios cientistas, sobretudo quando abordam problemas abertos, com soluções não estabelecidas. Cada um deles compreende de modo diferente (na maioria das vezes, e até um certo ponto) as questões discutidas, os problemas a resolver e até mesmo as proposições aceitas como resolvidas: em cada um deles um sistema de conhecimentos se estabeleceu com um ponto de vista próprio ou idiossincrático. Isso vai marcar sua abordagem particular e a manifestação de uma "verdade" que ainda não existia, e que portanto não bastava "colher", mas precisava se formar. Toda descoberta significativa é criação, obra individual e imprevisível. É por criação que o "novo" é formulado e trazido à luz. A ideia desse novo se forma primeiro no pensamento, antes de se manifestar e aparecer com evidência, como parte da representação objetiva. Nesse sentido, pode-se dizer, no que se refere aos conhecimentos, que a ideia precede o real (mais exatamente este real aqui, o real-para-nós, que se verá enriquecido pelo conhecimento novo).

Essas características individuais, que fazem que os caminhos em ciência se distingam, podem ser relacionadas, como em arte, a características de estilo. ${ }^{2}$ Podemos entender o estilo no sentido de um gênero ou de uma corrente numa determinada época, ou no sentido de uma característica individual, como em arte, em que ela é parte integrante da noção de criação: é nesse segundo sentido que o utilizo aqui. É possível evidenciar características de estilo no trabalho dos cientistas (ou, mais modestamente, dos pesquisadores científicos), sobretudo por meio de estudos comparativos entre trabalhos paralelos ou correlatos. ${ }^{3}$ Entre o dado conhecido a considerar, sua representação mental teórica com a formulação de problemas e a formação de proposições novas como soluções desses problemas, situa-se a "liberdade criadora" que faz intervir ao mesmo tempo o raciocínio e a imaginação.

Um dos aspectos mais importantes do pensamento científico, para além da simples gestão dos saberes adquiridos, para além da compreensão e da assimilação em profundidade que o termo "inteligibilidade" resume, é a produção de conhecimentos novos e o fato de essa produção ser o resultado de atos de criação intelectual. De que maneira esse aparecimento da novidade nas ideias (e depois nas coisas, seja pelo olhar que as ilumina, seja pelos novos objetos produzidos a partir dessas ideias) é possível e qual é sua dinâmica, eis uma questão que me parece ser uma das mais importantes da filosofia do conhecimento, e a história das ciências fornece elementos de resposta ou pelo menos fatos que correspondem à experiência humana em sua diversidade nesse campo.

Essa criação tem a ver mais com a representação das coisas do que com as próprias coisas, que preexistem às ideias que delas se faz. Mas a ausência de dis- 
tinção explícita entre as duas excluiu por muito tempo do vocabulário da ciência a palavra criação. A plena consciência da natureza simbólica dos conhecimentos científicos permite essa libertação e dá uma outra dimensão à questão da objetividade: a objetividade qualifica representações que se propõem a adequação ao que é. A existência das ciências como fato de história indica, portanto, que é possível criar no domínio dos conhecimentos objetivos, e mesmo criar conhecimentos objetivos.

O fenômeno de criação, tanto nas Artes como nas Ciências, torna particularmente manifesta a necessidade de nos referirmos ao sujeito. Nenhum efeito coletivo seria suficiente para explicar a invenção e a criação de formas novas nas ideias, nas representações, nos objetos produzidos, que não existiam anteriormente no universo das formas simbólicas nem no mundo real, e que eram mesmo impensáveis. Esse é sem dúvida o fato mais fundamental (o fato fundador) da ciência e da arte, e também da filosofia, que é pensamento reflexivo sobre as significações: elas se inventam no pensamento humano inscrito na história, as atividades nesses domínios se desenvolvendo segundo exigências específicas de cada um deles.

\section{A questão da objetividade}

A ciência possui como próprio a característica de ser uma atividade humana que procura explicar o mundo tal como ele é dado, produzir representações (simbólicas) que lhe sejam adequadas, e a inteligibilidade que assim se opera nos sujeitos individuais ou transcendentais é guiada pela exigência de objetividade, isto é, de adequação ao que é (para além da simples intersubjetividade, que seria um critério frágil dessa adequação), o que se traduz em termos de verdade.

Não é minimizar a importância da objetividade relacioná-la a uma exigência para o pensamento. A abordagem histórica oferece uma tonalidade interessante a esse problema. O que diferencia a história das ciências dos outros domínios da história (social, econômica, da arte, das religiões etc.) é essencialmente a perspectiva de objetividade inerente à ciência, isto é, a propriedade dessa atividade de produzir representações (descrição e explicação) como verdades racionais que escapam ao sujeito, ao mesmo tempo que dele se originam por sua atividade criadora, e que são trans-históricas embora resultem de uma atividade historicamente situada (Bourdieu, 2001).

No que se refere ao conhecimento, e muito particularmente o conhecimento científico, seria um erro confundir a objetividade com uma intersubjetividade. ${ }^{4}$ É verdade que as formas e as circunstâncias práticas dos julgamentos de objetividade se fazem segundo modalidades intersubjetivas e sociais, mas elas não se reduzem a tais modalidades, em razão de exigências que escapam às simples modalidades sociais (e certamente as "transcendem", no sentido "imanente" indicado mais acima).

O acordo de subjetividades não protege contra o erro, e a garantia de adequação "ao que é" é necessariamente mais exigente: ela deve se aplicar à relação do pensamento com o objeto que esse se propõe, antes da relação de 
pensamento a pensamento. Por sua vez, a objetividade e a cientificidade não se decidem por decreto, nem por um consenso ideológico ou local, como o mostram múltiplos exemplos ou casos da história, das desventuras de Copérnico e Galileu ao caso Lyssenko e à recente sociobiologia dos "genes de violência" ou outros (até mesmo de inferioridade social ou de pobreza...).

A objetividade, que é uma demanda, uma exigência para que o conhecimento não seja nem solipsista nem ilusório, é garantida (ou dada como tal) pela imposição de uma norma que constitui a regra para o pensamento: essa norma, sem se reduzir a algo de simplesmente social (pois se trata de conhecimento), se enuncia pelo menos no nível social (numa perspectiva de universalidade). Mas ela está em parte contida no pensamento interiorizado do sujeito, quando esse aceita uma forma de pensamento, um método, proposições de base e categorias gerais (o conjunto sendo concebido como de alcance universal) que constituem seu quadro de pensamento e orientam sua pesquisa pessoal. Contudo, ela é menos exigente no nível do sujeito que no nível social, no sentido de que a inteligibilidade se apoia nessa regra (norma, ou forma) sem se reduzir a ela, podendo, se necessário, ignorá-la ou rejeitá-la. No nível social da "comunidade" científica, a inteligibilidade não é uma noção definível com exatidão, a não ser, precisamente, por sua identificação à norma, que então não é mais que uma média e não possui significação individual. Uma "inteligibilidade-tipo" seria apenas um (mau) esquema de ensino, simplesmente "ideal" e irreal.

\section{Estilo, racionalidade, sentido}

A racionalidade acompanha o pensamento científico e estrutura os modos de inteligibilidade: ela tem por função a organização dos elementos de conhecimento. Não se deve confundi-la com a lógica, que ela ultrapassa, ao possibilitar a intuição intelectual como síntese racional imediata e ao tornar efetiva a noção de estilo científico que se desdobra sobre sua não univocidade, considerando um problema científico dado. A "liberdade lógica" do trabalho do pensamento científico, cara a Poincaré e a Einstein, é subjacente a essas noções (Paty, 1993, cap.9; 1999a).

Pode-se assim conceber que o exercício da racionalidade inerente ao pensamento científico é parte integrante da liberdade do pensamento, e mantém uma ligação com a vontade e com valores, sobretudo cognitivos. Para além dos conteúdos de ciência propriamente ditos, o pensamento humano propõe a significação e enuncia, em particular, que conhecer tem um sentido. Essas palavras, significação e sentido, designam categorias gerais do pensamento e de seus julgamentos que não correspondem a conteúdos particulares - de conhecimento ou de outros domínios do pensamento simbólico, como a arte -, mas os acompanham, os iluminam, por assim dizer, do interior. Na verdade, elas são inerentes a toda convocação de elementos de pensamento simbólico e qualificam a ordem de disposição destes últimos, dos quais recebem, por sua vez, reflexivamente a luz - e às vezes uma explicitação de suas definições. 
O conhecimento implica a ideia de sentido, mesmo se os dois não se confundem. Compreender é, para além de conhecer, para além dos saberes adquiridos, formar sentido, e é quando interiorizamos esse sentido que os conteúdos de conhecimento se tornam inteligíveis para nós: apropriamo-nos deles em nossos pensamentos. Disso resulta a diversidade das maneiras de compreender, segundo as particularidades individuais das pessoas, em torno de um mesmo núcleo de objetividade do qual falamos. Daí decorrem exigências a levar em conta no ensino. É daí que procede também a possibilidade de invenção e de criação, tanto em ciência como em arte.

Algumas das exigências de racionalidade foram sendo precisadas ao longo dos séculos, seja pela eliminação de vários saberes para fora do domínio científico (depois de terem legitimamente feito parte dele, como a astrologia ou a alquimia), seja pela extensão do pensamento científico a objetos que este não considerava até então, seja ainda pela modificação das abordagens dos objetos e dos fenômenos (concepções da natureza do raio luminoso, dos mundos celeste e sublunar, da conceitualização-matematização do movimento dos corpos etc.).

Pode-se mostrar, no que se refere à ciência, que a criação de conhecimentos novos é possível porque os quadros do pensamento e os modos mesmos da racionalidade se transformam ao se ampliarem (Paty, 2004b, 2005e).

\section{Historicidade das formas simbólicas e do conhecimento}

As ciências estão em transformação incessante, elas não são uniformes e de natureza semelhante umas em relação às outras. Cada cultura ou civilização se caracteriza por um sistema de conhecimentos e podemos reconhecer em cada uma, sob formas e com implicações diferentes, alguns traços do que chamamos ciência: conhecimentos sistemáticos que comparam, classificam, generalizam e raciocinam por abstração, mesmo se umas privilegiam mais que as outras o que para elas é concreto. A função do conhecimento é universal e ultrapassa, em todas as culturas, a utilidade prática (ver a esse respeito as ricas páginas de Claude Lévi-Strauss (1962) em La pensée sauvage).

A história das ciências, mas também a antropologia nos ensinam que existem outras ciências ou outros sistemas de conhecimento científico diferentes daquele que conhecemos, ligado à nossa forma de sociedade. A história das ciências não pode se limitar à de uma linha de cultura privilegiada; ela deve se interessar (o que já começou a ser feito há cerca de meio século) pela história das ciências do conjunto das culturas e das civilizações do planeta, e participar assim de uma história universal. ${ }^{5}$ Deve se aprofundar nisso por meio de estudos comparativos (Paty, 1999c, 2007a). Esses, quando existem, mostram que uma comunicação entre as culturas é possível, ou foi efetiva, por meio da história e da diversidade cultural (Paty, 1999b, 2005a, 2005d). A exigência intelectual trazida pela história ao campo das diversas culturas científicas é, nesse aspecto, a mesma: trata-se de compreender na historicidade, o que supõe uma medida comum entre regimes de racionalidade diferentes. 
Levar necessariamente em conta a alteridade dos conhecimentos, ilustrada pela universalidade do pensamento simbólico em sua relação com o mundo e pela função do racional sob regimes de pensamento e sistemas de cultura muito diversos, não implica, porém, a conversão a uma concepção relativista segundo a qual todos os sistemas de conhecimento seriam equivalentes. O conhecimento é uma função universal da atividade humana e todas as suas realizações, na sua diversidade, são reveladoras em certo grau e contêm lições respeitáveis e úteis. Alguns desses sistemas são, no entanto, mais próprios que outros a representar o mundo sem a projeção arbitrária de crenças, de afetividade e de subjetividade; de todos esses sistemas, o mais dinâmico e o mais amplo parece ser o que estabelece uma distinção nítida entre a racionalidade do conhecimento objetivante e as outras funções do pensamento humano. Ele é às vezes acusado, por isso mesmo, de desumanizar o mundo. Mas é que não se distingue com clareza o pensamento científico propriamente dito de outras formas da atividade humana ou de outras crenças que de fato contribuem, e de maneira mais eficaz, para desumanizar o mundo e até mesmo destruí-lo (por exemplo, a exploração econômica desenfreada da natureza e dos homens, ou as diversas formas de obscurantismo, religioso ou ideológico).

Esse sistema, no qual foram concebidas a ciência e a história tais como as consideramos no que precede, apresenta uma vantagem sobre os outros pelo lugar que concede, em princípio, à crítica explícita de si mesmo - precisamente porque não está mais colocado sob a autoridade de crenças. Resta saber se ele se oferece sempre os meios de pôr em prática essa saudável metodologia.

A historicidade atravessa todas as manifestações do pensamento e da ação humana, que se exprimem em sistemas de formas simbólicas segundo modalidades específicas a essas formas, transmissíveis e memorizadas (e com isso transpondo o tempo) graças às capacidades próprias do pensamento simbólico. Essas formas simbólicas abrangem conteúdos e significações que não se dissolvem no caráter histórico, mas, ao contrário, se constituem como tais por meio desse: pois é ele que tornou possível o arranjo de seus "materiais" (simbólicos e concretos) ao tornar efetiva, para esses conteúdos de sentido, a espessura da temporalidade.

Foi assim que se constituiu a "matéria do simbólico". Foi ao longo do desenvolvimento temporal ao longo das gerações e das trocas entre as culturas que progressivamente se criaram e se instalaram os elementos (conceituais) de inteligibilidade que permitem a assimilação num dado estado de conhecimento, esses elementos mesmos informando os do estado seguinte e o tornando possível. As ciências são também o fruto (e doravante o objeto) de uma história: seus conteúdos conceituais foram constituídos graças a essa história, por estratos de organizações sucessivas e possíveis de reencontrar sob o solo atual como camadas geológicas, apesar dos movimentos e ondulações de terreno que sobrevieram a seguir como outras tantas reorganizações.

Invocar a historicidade dos conteúdos (de uma ciência) é antes de tudo indicar que esses foram modelados e como que tecidos ao longo do curso do tempo, 
com materiais que correspondem a suas significações, dados e transformados, e cuja natureza de conteúdos de pensamento conceituais orientados a uma apreensão do mundo e das coisas resiste a qualquer redução externa (social), por ser imanente a si mesma no processo de elaboração deles. Parece legítimo dizer, ao contrário do que se compreende geralmente como "historicismo", 6 que só há historicidade em razão dos conteúdos, pois é a compreensão da maneira como esses se constituíram que permite conceber, precisamente, sua historicidade.

Devemos considerar, portanto, que a tomada de consciência da historicidade dos conhecimentos não é negadora da ideia de conteúdo de verdade dos conhecimentos. Admitiremos que os conteídos de verdade são relativos (em razão do caráter convencional da escolha inicial dos elementos simbólicos e de outros aspectos contingentes), ${ }^{7}$ mas que a ideia de verdade conserva um sentido, como expressão de uma exigência. A inteligibilidade tem por objeto tais conteúdos de verdade (relativa)

O ponto de vista da historicidade mesmo ajuda a formular melhor esses problemas, se iluminarmos seus pressupostos e as modalidades próprias da pesquisa histórica. Indiquemos aqui apenas alguns elementos. Um deles é a espécie de simetria, de que falamos a propósito do estilo, entre o sujeito historiador e aquele que se descobre sob o objeto de seu estudo. O conhecimento do presente, como sublinhava Marc Bloch (1949), ajuda a conhecer o passado, sendo inclusive sua condição primeira. A significação tem importância tanto nas formas do passado quanto nas do presente. E é preciso admitir também, apesar das rupturas e descontinuidades, uma espécie de continuidade mínima entre sistemas de representação em épocas diferentes da história, já que o último recebeu materiais do primeiro, em razão da "tecelagem" que evocamos. A incomensurabilidade dos sistemas conceituais e teóricos proclamada de Kuhn a Feyerabend ${ }^{8}$ tornaria impossível tal passagem e toda racionalidade desapareceria. Mas a história nos ensina que uma transmissão realmente existiu entre elementos significantes dos conteúdos de conhecimento (por exemplo, dos conceitos), não obstante a dessemelhança dos sistemas culturais nos quais cada um deles estava inserido em sua época. ${ }^{9}$ Se são elementos significantes, é que eles conservaram seu caráter racional, que constitui de fato a matéria mesma do trabalho do pensamento. Os elementos de um sistema transmigram a um outro e se transformam, graças ao trabalho daqueles que os pensam e os separam da sua suposta "axiomática" de partida. Trata-se aí de fatos de história, que é preciso explicar.

A consciência da historicidade estabelece a exigência da sua inteligibilidade, e a estabelece segundo condições epistêmicas que são aquelas específicas à história como disciplina. Por exemplo, segundo uma concepção própria do tempo dos homens em suas sociedades e em suas culturas, que é o da consciência histórica, do distanciamento e dos amadurecimentos. "O tempo da história", escrevia Marc Bloch $(1949$, p.5), "é o plasma no qual se banham os fenômenos e como que o lugar da sua inteligibilidade". É afirmar que a busca da significação 
da história estabelece essa significação como imanente à própria história. A consciência do tempo da história faz levar em conta, em história como também em história das ciências, as mudanças de significações em cada um dos diferentes momentos da história (para cada campo ou domínio considerado). Concluiremos disso que a inteligibilidade da história, embora essa se ocupe de um objeto muito diferente daquele das ciências exatas ou da natureza, mostra uma convergência com a inteligibilidade que estas últimas se propõem, tanto no presente como nos seus desenvolvimentos ao longo da história. Essa convergência reside no fato de a significação de seus conteúdos ser imanente a seu objeto mesmo (Paty, 2004a). Nesse sentido, parece-me lícito considerar a história como uma ciência (uma ciência humana e social, com sua especificidade ou sua episteme própria) que vem, com as outras, se inscrever no mundo e aumentar seu conteúdo.

\section{Notas}

l Em particular, tal como foi examinada filosoficamente por Granger (1968).

2 Sobre essas noções, ver Fleck (1934), Granger (1968).

3 Ver, em particular: Paty (1993, cap. 2), (1996, 1999a, 2005b, 2005c).

4 Descartes exprimiu, é verdade, a identidade delas (no Discurso do método), mas em seu sistema, no qual a razão está baseada na divindade.

5 Ver, por exemplo, Needham (1993); Jami et al. (1992); Habib \& Raina (1999); Saldaña (2005), Paty (1999b).

6 Entendo aqui por "historicismo" as posições que minimizam ou apagam as considerações racionais e teóricas em nome da fatualidade da história.

7 Constatação feita por Pascal, retomada ou redescoberta por Willard van Orman Quine (1969, 1990).

8 Ver em particular Kuhn $(1977,2000)$.

9 Cf., por exemplo, Paty (2001a, 2005a, 2005d).

\section{Referências}

BLOCH, M. Apologie pour l'histoire ou Métier d'historien, Cahiers des Annales, 1949 (Manuscrito original: 1941. $1^{\mathrm{a}}$ publ., póstuma, preparada por Lucien Febvre); edição crítica preparada por Etienne Bloch e Jacques Le Goff. Armand Colin: Paris, 1993.

BOURDIEU, P. Science de la science et réflexivité. Paris: Raisons d'Agir, 2001.

CASSIRER, E. Philosophie der symbolischen Formen, 3 v. 1923, 1924, 1929. Trad. fr. por Ole Hansen-Love, Jean Lacoste e Claude Fronty. La philosophie des formes symboliques. Paris: Minuit, 1972. 3v. (Collection "Le sens commun")

FLECK, L. Entstehung und Entwicklung einer wissenschaftlichen Tatsache, 1934). Trad. fr. Genèse et développement d'un fait scientifique. Paris: Belles Lettres, 2005.

GRANGER, G.-G. Essai d'une philosophie du style. Paris: Armand Colin, 1968 [reed. Paris: Odile Jacob, 1988]. 
HABIB, S. I.; RAINA, D. (Ed.) Situating the history of science: Dialogues with Joseph Needham. New Delhi: Oxford University Press, 1999.

JAMI, C. et al. (Ed.) Science and empires, Dordrecht: Kluwer, 1992.

KUHN, T. The essential tension. Chicago: The University of Chicago Press, 1977.

Dogma contra critica. Mondi possibili nella storia della scienza. A cura di Stefano Gattei. Milano: Raffaello Cortina Editore, 2000. (Coleção de textos publicados separadamente em inglês; inédito em livro em inglês)

LÉVI-STRAUSS, C. La pensée sauvage. Paris: Plon, 1962.

NEEDHAM, J. Dialogues des civilisations Chine-Occident. Pour une histoire oecuménique des sciences. Org. por G. Métaillé. Paris: La Découverte, 1993.

PATY, M. Einstein philosophe. La physique comme pratique philosophique. Paris: Presses Universitaires de France, 1993.

. Le style d'Einstein, la nature du travail scientifique et le problème de la décou-

verte. Revue Philosophique de Louvain, v,94, n.3, p.447-70, ago. 1996.

A ideia de universalidade da ciência e sua crítica filosófica e histórica. Trad. Pablo Ruben Mariconda. Discurso, São Paulo, n.28, p.7-60, 1997.

La création scientifique selon Poincaré et Einstein. In: SERFATI, M. (Ed.) La recherche de la vérité. Paris: ACL-Éditions Du Kangourou, 1999a. p.241-280. Col. L'Écriture des Mathématiques

L'universalité de la science. Une idée philosophique à l'épreuve de l'histoire. Mâat. Revue Africaine de Philosophie, n.1, p.1-26, avril 1999b.

Comparative history of modern science and the context of dependency. Trad. do francês por Nicholas Flay, Science, Technology and Society. An International Journal Devoted to the Developping World (New Delhi: Sage Publications), v.4, n.2, p.171-204, 1999c. [Original em francês: L'histoire comparative des sciences modernes et le contexte de dépendance. Convergencia. Revista de Ciencias Sociales, Cidade do México, ano 8, n,24, p.11-48, jan.-abr. 2001].

Les concepts de la physique: contenus rationnels et constructions dans l'histoire. Principia, Florianópolis, v.5, n.1-2, p.209-40, jun.-dez. 2001 la.

. A criação científica segundo Poincaré e Einstein. Trad. Sérgio Alcides. Estudos Avançados, São Paulo, v.15, n.41, p.157-92. Jan.-abr., 2001 b.

. Matière et nécessité dans la connaissance scientifique. In: DUBESSY, J. et al. (Ed.) Les matérialistes (et leurs détracteurs). Paris: Syllepses, 2004a. p.155-80.

Nouveauté et émergence dans la quête des fondements. Principia, Revista de Epistemologia, Florianópolis, v.8, n.1, p.19-54, 2004b.

. The question of rationality in front of the diversity of knowledges practices. In: D'AMBROSIO, U. (Ed.) Cultural diversity: new perspectives in the History of Sciences [in SALDAÑA, J. J. (Ed.) Science and Cultural Diversity. In: XXI INTERNATIONAL CONGRESS OF HISTORY OF SCIENCE. México, 2001. Proceedings. Universidad Autónoma de México \& Sociedad Mexicana de Historia de la Ciencia y de la Tecnologia, CD-Rom, México, 2005a, v.42, p.3261-81.

Pensée rationelle et création scientifique chez Poincaré. In: COLLOQUE 
HENRI POINCARÉ “SCIENCE ET PENSÉES”, 17 de janeiro 2005, CD-Rom, Fondation Sophia-Antipolis, 2005b, 19p.

Einstein 1905: La théorie de la relativité restreinte comme création scientifique. Cahiers Rationalistes, n.579, p.6-16, nov-dez 2005c / n.580, p.6-18, jan.-fev. 2006. -dez. 2005d.

Intelligibilité rationnelle et historicité. La Pensée. Paris, n.344, p.113-32, out.-

. Des Fondements vers l'avant. Sur la rationalité des mathématiques et des sciences formalisées. Philosophia Scientiae, Nancy 2, Paris, v.9, n.2, p.109-30, 2005e.

Os conceitos da física: conteúdos racionais e construções na história. Trad. Silvia Waisse Priven. In: AFFONSO-GOLDFARB, A. M. et al. (Ed.) Atas do Colóquio Cesima Ano X (outubro de 2005), Cesima \&PUC/SP, São Paulo, CD-Rom, 2006a, cap. 29, p.1-35.

- Materia e necessidade no conhecimento científico. Trad. Claudemir Roque Tossato e Mauricio de Carvalho Ramos. Scientiae Studia (Revista Latino-Americana de Filosofia e História da Ciência, Sao Paulo, v.4, n.4, p.589-613, 2006 b.

Rationalités comparées des contenus mathématiques. Sur les travaux de Roshdi Rashed, ou: La philosophie dans le champ de l'histoire des sciences, Dogma. Revue des Revues, Epistémologie, 2007. 36p. Disponível em: <http://dogma.free.fr>. (Exposto em Colloques des sciences arabes, Damasco, Síria, 1-4 de novembro 2002.)

QUINE, W. van O. Ontological Relativity and Other Essays. New York: Columbia University Press, 1969. [Trad. Jean Largeault, Relativité de l'ontologie et autres essais. Paris: Aubier-Montaigne, 1977]

Pursuit of Truth. Cambridge Mass.: Harvard University Press, 1990. [Trad. La poursuite de la vérité. Trad. Maurice Clavelin. Paris: Seuil, 1993]

SALDAÑA, J.-J. (Ed.) Science and Cultural Diversity. In: XXI INTERNATIONAL CONGRESS OF HISTORY OF SCIENCE. México, 2001. Proceedings. México, Universidad Autónoma de México \& Sociedad Mexicana de Historia de la Ciencia y de la Tecnologia, CD-Rom, México, 2005.

VEYNE, Comment on écrit l'histoire (1971), seguido de Foucault révolutionne l'histoire (1978). Paris: Seuil, 1979. (Col. "Points")

RESUMO - Ao considerar o conhecimento científico como uma forma de pensamento simbólico, entende-se com isso não simples sistemas de signos, mas conteúdos de pensamento (expressos por conceitos) ligados entre si e que fazem sentido, que são, no espaço das representações mentais, os substitutos do "dado objetivo" que se supõe subjazer à experiência que fazemos do "mundo" pelos sentidos e, nesse nível indissociavelmente, pelo entendimento. Esse pensamento simbólico adquire densidade e consistência pela "tecelagem" realizada graças ao trabalho dos pensamentos individuais que se comunicam, social e culturalmente, inscritos no tempo da história. Da tensão dinâmica entre o sujeito do conhecimento, que busca a inteligibilidade (pela operação de sua razão), e a objetividade dos conteúdos que ele se propõe (inicialmente dados, depois 
modificados ou produzidos), resulta o movimento do pensamento científico e a transformação dos conhecimentos. Esse trabalho do pensamento simbólico é marcado por um estilo próprio a cada um, mas que em parte pode ser comum em contextos, escolas ou tradições. Em ciência e em história das ciências, o estilo intervém em dois níveis: o da abordagem "objetal” da produção das obras pelos cientistas e o da abordagem "reflexiva" da história epistemológica e da filosofia, que se interrogam sobre a significação tanto dos próprios conteúdos de conhecimento quanto do pensamento racional, simbólico, cuja função é manifestá-los.

Palavras-Chave: Conhecimento, Criação, Estilo, História, Inteligibilidade, Objetividade, Pensamento simbólico, Razão, Sujeito, Tensão, Tecelagem dos conhecimentos.

ABSTRACT - By considering scientific knowledge as a form of symbolic thought, we do not mean by the latter simply systems of signs, but thought contents (expressed by concepts) related between them and providing meaning; they are, in the space of mental representations, the substitutes of the "objectively given» that one supposes to underly the experience of the «world» done through the senses and the understanding, both being indissociable at this level. This symbolic thought gets density and consistence in the «weaving» that is made, through the work of the individuals thoughts put together in social and cultural communication, and immersed in the time of history. The dynamical tension between the subject of knowledge, who is looking for intelligibility (by the operations of his reasoning), and the objectivity he aims at of the knowledge contents (first given to him, and then modified or renewed by him), produces as an effect the movement of scientific thought and the transformations of knowledge. This work of the symbolic thought is characterized by a style proper to each acting subject, but which may exhibit some common features in given contexts, schools or traditions. In science and in history of science, style intervenes at two levels : that one of the "objectal» approach of the production of works by scientists, and that one of the "reflexive » approach by epistemological history and by philosophy, which inquire about the meaning of the knowledge contents themselves as well as about that of the rational, symbolic, thought whose function is to bring them to light.

KErWORDS: Creation, History, Intelligibility, Knowledge, Objectivity, Reason, Style, Subject, Symbolic thought, Tension, Weaving of knowledges.

Michel Paty é professor visitante no Departamento de Filosofia da FFLCH-USP e diretor emérito de pesquisa no Centre National de la Recherche Scientifique (equipe REHSEIS, UMR 7596, CNRS e Universidade Paris 7-Denis Diderot). É autor de Einstein philosophe (Presses Universitaires de France, 1993), A matéria roubada (Edusp, 1995), A ciência nas relações Brasil-França (1850-1950) (col. Edusp, 1996), La physique du XXe siècle (Les Ulis, 2003); D'Alembert (Estação Liberdade, 2004). @ - michel.paty@univ-paris-diderot.fr

Tradução de Paulo Neves. O original em francês - "Du style en science et en histoire des sciences" - encontra-se a disposição no IEA-USP para eventual consulta.

Recebido em 28.10.2010 e aceito em 26.11.2010. 